\title{
As mudanças na historiografia francesa durante as primeiras décadas do século XIX
}

The Changes in French Historiography during the First Decades of the $19^{\text {th }}$ Century

MEDEIROS, Bruno Franco. Plagiário, à maneira de todos os historiadores. Jundiaí: Paco Editorial, 2012. 192 p.

\section{Cleonice Elias da Silva}

cleoelias28@gmail.com

Mestranda

Pontifícia Universidade Católica de São Paulo

Rua Alvaro Troppmair, 27 - Jardim Maria Sampaio

05790-100 - São Paulo - SP

Brasil

Palavras-chave

Historiografia do século XIX; Historiografia brasileira; Historiografia francesa.

Keywords

$19^{\text {th }}$ century historiography; Brazilian historiography; French historiography. 
A obra Plagiário, à maneira de todos os historiadores, do historiador Bruno Franco Medeiros, é o resultado de sua pesquisa de mestrado realizada no departamento de História da Faculdade de Filosofia, Letras e Ciências Humanas da Universidade de São Paulo (FFLCH-USP), finalizada em 2011. O trabalho realizado por Medeiros é um estudo que visou analisar os procedimentos metodológicos utilizados na pesquisa e na escrita da história durante a primeira metade do século XIX, traçando paralelos e distanciamentos com a produção de alguns intelectuais do século anterior.

Ao direcionar sua pesquisa para as obras do historiador francês Alphonse de Beauchamp (1767-1832), para sua maneira peculiar de escrever a história de seu tempo e para as críticas feitas constantemente aos seus trabalhos realizados entre os também historiadores franceses e os de outras nacionalidades, como o Visconde de Porto Seguro (Francisco Adolfo Varnhagen), Medeiros evidencia as transformações que gradativamente influíram de forma significativa nas mudanças dos métodos utilizados pelos historiadores para escolherem e analisarem suas fontes e escreverem seus textos.

O livro está organizado em duas partes, e cada uma delas possui três capítulos. Na primeira, L'Europe Finit, L'Amérique Commence: História, Colônias, Impérios, Bruno Medeiros apresenta elementos referentes à produção na historiografia francesa sobre alguns dos aspectos políticos que marcaram o período pós-Revolução Francesa. Dentre as obras produzidas nesse período é citada a de Philippe-Paul Ségur (1780-1873), general que

272 participou da Campanha da Rússia e presenciou o fracasso francês, publicando, em 1824, Historie de Napoléon et de la Grande Armée en 1812. Esta obra, que foi analisada por Beauchamp no ano seguinte, pode ser considerada como o ponto de partida selecionado por Bruno Medeiros para analisar a produção historiográfica francesa de inícios do século XIX no que diz respeito aos acontecimentos próximos, isto é, à história contemporânea, principal campo de interesse de Beauchamp.

$\mathrm{Na}$ análise do trabalho de Ségur, Beauchamp, entre outras considerações, afirma que "os grandes eventos geram grandes historiadores", enaltecendo a produção dos historiadores da Antiguidade tais como Tácito e Tito-Lívio, os quais, para o autor, deveriam ser tomados como exemplos a ser seguidos por aqueles que pretendiam escrever sobre a história. Nesse sentido, a perspectiva de Beauchamp era a de que a história deveria "instruir os homens Ihes revelando as causas dos eventos e suas sequências infalíveis: é por isso, sobretudo, que a história torna-se a escola dos grandes capitães e homens de Estado" (MEDEIROS 2012, p. 28, grifos no original).

Assim como elucida Medeiros, Beauchamp não apenas se referia aos métodos e perspectivas de Ségur, como também aos seus próprios. O historiador francês estudado por Medeiros, entre outros trabalhos, produziu alguns escritos referentes à Revolução Francesa. Cabe destacar, em linhas gerais, que Beauchamp pode ser considerado um "conservador" e que enxergava na Restauração da Monarquia as melhores possibilidades de estabilidade política para a França. Tanto é assim que o conceito de 
revolução utilizado por ele dizia respeito ao restabelecimento de uma antiga ordem. ${ }^{1}$

Beauchamp utilizava como principais fontes para a realização de suas pesquisas os testemunhos oculares, principais "vias documentais" para a produção da história do presente ou do passado recente; esses testemunhos foram considerados como fontes legítimas que contribuíam para o caráter verossimilhante do relato de um determinado acontecimento histórico. No início da primeira parte de seu livro Medeiros apresenta uma discussão importante e necessária sobre a consciência por parte dos historiadores da "impossibilidade de se dizer toda a verdade". Desde Luciano e Cícero caberia ao historiador, apoiado no bom senso e na sua "ética", sempre dizer a verdade evitando entrar no campo das fabulações. Beauchamp reconhecia a dificuldade de lidar com a verdade no campo de produção historiográfico e, por essa razão, assim como menciona Medeiros, ele utilizava a metáfora do espelho, sendo essa uma justificativa usada por ele para explicar os seus métodos e rebater as críticas das quais foi alvo: "A imagem que o historiador deveria refletir em seu relato, semelhante ao espelho, não deveria ser deturpada ou deformada, uma fórmula que se manifestava aos menos desde Luciano" (MEDEIROS 2012, p. 45).

Apesar de esses historiadores interessados pela história contemporânea apresentarem suas justificativas a respeito de importância de seu objeto de estudo, ocorreu no meio intelectual francês de inícios do século XIX uma resistência a esse tipo de produção. Um exemplo claro disso é o fato de que até a Restauração, em 1815, nenhum relato sobre a Vendeia havia sido publicado. Ainda apoiando-se nas constatações de Koselleck, Medeiros (2012, p. 50) explica que as "objeções" da escrita da história no período correspondente aos finais do século XVIII não seriam necessariamente resultado do momento político vivenciado, mas se deveriam muito mais às mudanças na experiência da realidade histórica e de sua "reestruturação temporal". Essas hipóteses do teórico alemão a respeito da temporalização da história durante a Época Moderna, período delimitado entre meados do século XVIII e meados do XIX, justifica-se pela aceleração do "tempo que caracteriza nossa modernidade"; diante disso, a história contemporânea acaba por perder gradativamente a sua importância.

Cabe ressaltar que por mais que no século XIX a história contemporânea tenha se tornado alvo de críticas constantes, do século XX até o atual, é ela um dos principais campos de interesse dos historiadores. Conforme destaca Luciana Silveira de Aragão e Frota (2012, p. 132), é possível perceber no início do século XX o "desenraizamento da sociedade clássica e tradicional" e nota-se "a percepção de que isto impunha uma confrontação como o passado precedente que parecia fornecer uma etnologia concernente a nossa própria sociedade". Aragão afirma que é imposto à história "um desenraizamento acelerado" que obriga a disciplina

\footnotetext{
1 "[...] No prefácio de sua obra ele afirmou que 'a revolução francesa começou pela derrubada do Trono, e ela somente poderia terminar pelo seu restabelecimento [...]'. O conceito de revolução mobilizado por Beauchamp e Nettement se afasta das tentativas de caracterizá-lo a partir de seu significado moderno, ou seja, o de revolução como mudança radical a partir de transformações políticas e sociais. A Revolução Francesa foi lida como restauração porque ambos ainda se apoiavam no substrato natural daquele conceito, ou seja, no movimento cíclico regular dos astros celestes [...]" (MEDEIROS 2012, p. 31-32).
} 
a se renovar; um medo de separação do passado "num tipo de sociedade onde a massa dos acontecimentos e a sua repercussão são difíceis de reintegrar a nosso cotidiano". Em contrapartida, surgem novas possibilidades para o historiador a partir de uma expectativa que considera que "ela [a história] possa fornecer os mistérios do tempo em que vivemos". Em suma, por mérito, cabe lembrar os trabalhos do historiador Eric Hobsbawm sobre o atribulado século XX. Segundo a mesma autora, Hobsbawm conseguiu realizar uma análise concisa e prática, estudando o século a partir de uma divisão que considera três eras.

No segundo capítulo da primeira parte de seu livro Medeiros nos apresenta aspectos do trabalho de Beauchamp sobre a história do Brasil, Historie du Brésil, publicado em 1815, e os debates que marcaram o lançamento da obra. Em período anterior (1808), o historiador havia publicado Histoire de la conquête et de révolutions du Pérou. Em síntese, destaco que Beauchamp considerou que, para escrever sobre a história do Brasil, fazia-se necessário também debruçar-se sobre a história de Portugal; entretanto, tal história deveria comportar-se como um acessório, pois os hábitos e costumes do Brasil se diferenciavam dos da Europa. Todavia, escrever sobre a história do Novo Mundo era uma via possível para revigorar-se a história da Europa. ${ }^{2}$ De fato, alguns autores de finais do século XVIII enxergavam o seu esgotamento. Chateaubriand, entre outros, por exemplo, viajou para o continente americano em 1791, retornando no começo de 1792, sendo que suas impressões sobre essa viagem foram publicadas em 1797 em seu Essai Historique. Uma característica desses relatos de viagem é que não tiveram como foco a América portuguesa, e, por essa razão, é possível atribuir a Beauchamp um pioneirismo apesar de seu trabalho ter sido criticado pelos historiadores brasileiros e até mesmo pelos seus compatriotas.

A ênfase do trabalho de Beauchamp recaiu sobre a história política e militar do Brasil. A obra foi dividida em três volumes e 44 livros. E, apesar de os letrados portugueses (como Marques Leão, que traduziu a obra do historiador francês) reconhecerem alguns defeitos na sua produção, os escritos de Beauchamp convergiram para as pretensões desses letrados engajados no projeto de regeneração de Portugal. Diante disso, Medeiros (2012, p. 64) sublinha que: "[...] Somente a constatação de que Portugal poderia regenerar sua história no Brasil permitira que Marques Leão afirmasse que a Histoire du Brésil de Beauchamp bastaria como História de Portugal para ser lida com gosto".

Sem reservar nesta resenha o espaço que essa discussão merece, pontuo em linhas gerais, a partir das afirmações de Medeiros (2012, p. 60), que a convicção de que Portugal passava por uma fase de decadência em inícios do século XIX não teria como motivação o fato de Portugal não saber explorar suas colônias, mas o fato de não ter conseguido se desenvolver paralelamente a elas. Sendo assim, a política do

\footnotetext{
2 "[...] É importante salientar a importância que os periódicos tiveram nas discussões a respeito dos problemas confrontados por Portugal no início do século XIX [...]. O Brasil passa a ser considerado como um lugar privilegiado para os planos de sua regeneração e restauração do passado glorioso de Portugal: desde então passava a representar a sede da monarquia portuguesa ressuscitada. As palavras inaugurais de Historie du Brésil de Beauchamp já deixavam isso claro" (MEDEIROS 2012, p. 62). Nesse sentido, José CañizaresEsguerra (2012, p. 19) afirma que a produção historiográfica da Espanha sobre o Novo Mundo no século XVIII visava a uma reconstrução da sua própria identidade.
} 
reformismo ilustrado de Portugal passou a defender que, para o desenvolvimento da metrópole, uma condição imprescindível era a incorporação dos resultados obtidos com a exploração colonial. Como bem defende Fernando Novais, "o sistema colonial" não deixou de ser o principal articulador da relação entre metrópole e colônia, e o projeto do reformismo ilustrado português nessa conjuntura almejava a integração entre o desenvolvimento metropolitano e o colonial.

O Brasil despontava no cenário internacional como um dos impérios mais florescentes do mundo, e um elo foi estabelecido entre esse país e a França, o qual poderia ser promissor para ambos:

[...] De todo modo, se o velho mundo imprimiu sua forma ao novo durante o processo de colonização, defendia-se na época que ele deveria também conceder o modelo das novas entidades políticas nascentes. Nesse caso, a defesa da monarquia constitucional regia o tom desse intercâmbio (MEDEIROS 2012, p. 75).

Apesar do reconhecimento da importância econômica e política do Brasil, agora não mais colônia, e sim império, muitos elementos que regeram a lógica do sistema colonial entre os séculos XVI, XVII e XVIII se mantiveram vivos, ora mais atenuados, ora mais evidentes. A restauração da Europa necessitava apoiar-se nas promissoras possibilidades de desenvolvimento dos "Impérios" do Novo Mundo; entretanto, permanecia vigente o ideário que afirmava que a Europa, civilizada por natureza, seria a principal orientadora do intercâmbio estabelecido.

No terceiro capítulo dessa primeira parte Medeiros foca-se na recepção da obra de Beauchamp entre os intelectuais brasileiros engajados com os projetos de constituição de um discurso histórico a respeito do Brasil e na repercussão negativa do trabalho realizado pelo General José Inácio de Abreu e Lima (17941869), Compêndio da História do Brasil, publicado em 1843 (uma edição especial foi publicada no ano seguinte). O principal objetivo da obra foi o de ser o livro oficial da História do Brasil no Colégio Dom Pedro II, função que manteve até 1861. Apesar de a intelligentsia do Instituto Histórico e Geográfico Brasileiro (IHGB) ter apontado uma série de problemas presentes no mencionado Compêndio..., durante um longo período ele foi a referência para o ensino da história durante a época do Império. Diante disso, percebemos um âmbito repleto de "disputas" e até mesmo de "contradições" no que diz respeito à produção de um discurso histórico sobre o Brasil, ou, em outras palavras, à constituição de uma história oficial.

Entre outros fatores, a má recepção entre os sócios do IHGB da obra de Abreu Lima, que se apoiou em muitos dos aspectos estruturadores e norteadores do livro de Beauchamp, que também foram criticados pelos referidos sócios, ${ }^{3}$ esse acusado de ter plagiado o trabalho do historiador inglês Robert Southey (1774-1843), aponta para as discussões a respeito de quais procedimentos, estes ainda não bem definidos, que deveriam ser seguidos na pesquisa e na

\footnotetext{
${ }^{3}$ Apesar de Beauchamp não ter sido bem recebido entre os sócios do IHGB na primeira metade do século XIX, alguns historiadores franceses estabeleceram intercâmbios com o Instituto. No relatório publicado por Manoel Ferreira Lagos (secretário do Instituto) sobre as atividades do IHGB no ano de 1846, é possível perceber essas afinidades entre os historiadores brasileiros e os franceses (MEDEIROS 2012, p. 103).
} 
escrita da história do Brasil na primeira metade do século XIX. Em linhas gerais, um dos principais alvos das críticas ao trabalho de Abreu Lima foi o fato de ele ter se baseado em trabalhos já realizados e não na análise de documentos. Os principais autores consultados foram o padre Manoel Aires de Casal (17241821), Robert Southey (1774-1843), Alphonse Beauchamp e Henrique Luís Niemeyer Bellegarde (1802-1839).

Varnhagen era um crítico contundente não apenas de Abreu Lima, mas também, conforme mencionado no início da resenha, de Beauchamp. Discordava de Abreu Lima, que defendia a existência de um grau de concordância entre a literatura portuguesa e a brasileira; já Varnhagen preconizava a inexistência de uma literatura própria no Brasil. Mesmo criticando o trabalho de Beauchamp sobre a história do Brasil, Varnhagen, de forma bastante similar a ele, esforçou-se em "reafirmar as continuidades históricas entre Brasil e a antiga metrópole" (MEDEIROS 2012, p. 97).

Varnhagen, além de tecer ácidas críticas a Beauchamp e Abreu Lima, almejava que a sua obra História Geral, cuja segunda edição data de 1877, fosse aceita pelos sócios do IHGB como a história oficial do Brasil. Tal ambição não se concretizou. Entretanto, esse fato não o impediu de continuar afirmando que sua obra era pioneira: "O ótimo é inimigo do menos mal. Não era justo que enquanto não poderíamos alcançar o ótimo, nos contentássemos com o péssimo, que péssimo era não possuir a noção histórica geral, digna deste nome, sisuda e imparcialidade escrita" (apud MEDEIROS 2012, p. 102).

276 Na segunda parte de sua obra, "O desafio da prova: plágio e escrita da História", Medeiros tenta mapear as discussões e o estabelecimento de diretrizes na França sobre a prática e o julgamento do plágio. Esse mapeamento é importante para entendermos o porquê de Beauchamp ter sido em vários momentos de sua carreira acusado de plagiário, cabendo a nós leitores concordarmos ou não com as acusações. Ressalto que os procedimentos utilizados pelo historiador francês em suas pesquisas e na sua escrita da história estão arraigados no modelo antigo, o qual foi gradativamente caindo em desuso no meio da historiografia francesa de inícios do século XIX. E é possível estabelecer ligações entre essas transformações e as normatizações legais a respeito da prática do plágio.

Não estenderei as discussões ao que diz respeito às leis estabelecidas para orientar os julgamentos de obras que poderiam ser ou não plágios de outras. Destaco apenas que a consolidação de leis a respeito da propriedade autoral se deu de forma muito lenta, talvez devido às decisões estarem sob a incumbência da República das Letras, que, para Medeiros (2012, p. 120), forjava seus mecanismos críticos. Diante disso, debates acalorados foram travados tanto por aqueles que se defendiam da acusação de plágio como por aqueles que se sentiam lesados por terem seus trabalhos usurpados por outros autores. Medeiros apresenta alguns casos de acusações de plágios que foram a julgamento nas instâncias jurídicas.

Entre as acusações de plágio direcionadas a Beauchamp estão as referentes à biografia escrita por ele de Ali Pacha, vizir de Janina, morto em 1822. A obra recebeu o título Vie d'Ali Pacha, Visir de Janina, Surnomé Aslan, ou Le Lion. 
O historiador defende-se das acusações com uma afirmativa, e por que não conclusão, a respeito do trabalho do historiador, a qual inspirou o título do livro de Bruno Medeiros.

Ter escrito um assunto histórico não constitui privilégio de explorá-lo exclusivamente. Os eventos públicos pertencem a todos os escritores que queiram se ocupar deles. Havia uma Vida de Ali Pacha antes daquela de M. Beauchamp? Não, existiam somente fragmentos esparsos, memórias isoladas, relações incompletas. Se tomar esses materiais, para lhes moldar e Ihes arranjar, é roubar, M. Beauchamp, que fez uma Vida de Ali Pacha escrita com fervor, rapidez e clareza, é um plagiário à maneira de todos os historiadores (MEDEIROS 2012, p. 125).

Apesar de o jornal Le Quotidienne ter afirmado que Beauchamp citara as fontes consultadas, Medeiros (2012, p. 127) sublinha que um dos principais alvos das críticas foi justamente a ausência das referências, e isso indica que surgiam nesse contexto novas demandas que deveriam ser seguidas pelos historiadores ao citarem as fontes analisadas em suas pesquisas. Passa a ser exigido por parte dos historiadores que não apenas se compile uma série de documentos ou que se reproduzam as reflexões de outros autores, tal como o fez Abreu Lima, mas que se comprove de onde são tiradas as informações.

Para Marc Bloch (2001), os documentos são vestígios e não dados rígidos, como consideravam os positivistas de finais do século XIX. A crítica da história pode ser definida como um procedimento a partir do qual o historiador analisa, questiona os documentos, uma vez que esses por si sós não dizem nada. Por mais que o referido medievalista enfatizasse o caráter científico da história, ela também possuiria características de cunho poético. Enxergo algumas convergências entre certas perspectivas defendidas por Bloch e a prática historiográfica de Beauchamp; por exemplo, o primeiro defendia que o objeto central da história era o homem no tempo, que o presente estava ancorado na história. Dessa forma, o presente poderia ser mais bem compreendido ao considerar-se o passado, e, no movimento inverso, mas não contraditório, o passado também poderia ser elucidado pelo presente. No entanto, mesmo reconhecendo as convergências de perspectivas entres esses dois historiadores franceses, não negligencio o fato de Bloch ser um medievalista e de estar inserido na Escola dos Annales, responsável pela "revolução" no campo de produção historiográfico não apenas francês como também de outras nacionalidades. Por outro lado, Beauchamp encontrava-se inserido em um contexto intelectual, cujos métodos eram considerados desqualificados, pois emergia em inícios do século XIX uma nova dinâmica no campo de produção da pesquisa histórica que convergia para a necessidade de romper com os antigos parâmetros e estabelecer e consolidar novos.

No segundo capítulo da segunda parte do livro Medeiros nos apresenta a apologia de Beauchamp. Na tentativa de rebater as críticas de plágio, ele articula uma série de argumentos visando dar legitimidade aos seus procedimentos metodológicos e à sua escrita. Tendo em vista as transformações ocorridas no século XIX Medeiros conclui que "a escrita da história e plágio iluminam-se mutuamente [...]". Segundo Beauchamp, as memórias "são para o historiador 
o que as cores são para o pintor, somente por sua mistura e fusão o quadro da história que daí resulta forma uma composição completa" (MEDEIROS 2012, p. 129-130). Cabe comentar que Abreu Lima reproduziu tal metáfora a respeito das escolhas metodológicas feitas por ele para a elaboração de seu Compêndio.

Mably, um historiador moderno, era citado por Beauchamp, pois assim como ele, Mably era admirador dos historiadores da Antiguidade. Ele admirava a nobreza e a grandeza dos antigos e considerava a história antiga detentora de um caráter exemplar. A história para ele era uma narrativa e dependia apenas do historiador a "organização de um sentido concedido aos eventos". A trama narrativa bem-estruturada em seus procedimentos de composição era o elemento essencial para legitimar o que o historiador dizia (MEDEIROS 2012, p. 135).

Conforme foi possível perceber pela apresentação de algumas críticas dirigidas aos trabalhos de Beauchamp, esses métodos defendidos por Mably e "admirados" por aquele, desde início do século XIX, começaram a ser veementemente criticados. La Brenellerie, por exemplo, era um dos críticos e aconselhava o historiador "a não experimentar os efeitos que as diferentes obras de Salústio, Tito-Lívio ou Plutarco poderiam provocar [...]" (MEDEIROS 2012, p. 139).

Era preciso que o modelo dos historiadores da Antiguidade fosse superado para que, dessa forma, o historiador pudesse "pintar o grande quadro da humanidade"; para tanto, ele não deveria seguir o método de um poeta e de um pintor, mas, segundo La Brenellerie, as omissões deviam ser evitadas e, por mais rigorosa que fosse, a verdade teria de ser "revelada" sem se correr os riscos de 278 cometer desconfigurações "para ser mais eloquente ou moralista, nem impondo-Ihe seu espírito de partido ou de sistema". Em síntese, o que passa a estar em voga é a defesa de uma imparcialidade na produção do conhecimento histórico.

No último capítulo de sua obra Medeiros apresenta à guisa de discussão elementos relacionados aos estilos a serem adotados pelos historiadores ao escreverem seus textos. Na seção "História, Falsidade, Romance: e verdade em primeiro lugar, o estilo depois", adota com fonte para desenvolver as suas reflexões o relatório produzido pelo júri da classe História e Literatura Antiga e Moderna, publicado em novembro de 1810, no qual há uma explicação sobre os requisitos considerados para avaliação das obras que participavam da premiação no Institut de France, realizada em 1809. Em linhas gerais, o relatório apresentava o esclarecimento de "que a história se dividia em várias classes e cada uma tinha gêneros e graus particulares de interesses e utilidade, cuja execução demandava talentos diversos [...]". O júri, ao avaliar as obras finalistas, traçava paralelos entre a história e a poesia, uma vez que "o interesse da narração nascia quase exclusivamente dos detalhes [...]" (MEDEIROS 2012, p. 147).

Uma das seis obras que concorreu ao prêmio decenal do Institut de France acabou tornando-se alvo de um debate acalorado: trata-se da obra Histoire de la diplomatie française, de Gaëtam de Raxis Flasan. Para Medeiros (2012, p. 148), esse debate aponta para as divergências entre os dois tipos de escrita da história que existiam na França no século XIX. Independentemente do tipo a ser adotado, o que deveria ser considerado é que a verdade era a prioridade e o estilo ficaria em um segundo plano. 
Beauchamp escreveu um artigo criticando Flasan por ter tentado estabelecer regras para a escrita da história, mais especificamente, para a história diplomática. Para ele, os modelos já haviam sido estabelecidos por Cícero e Luciano e, posteriormente, por Fénelon, Rollin e La Harpe, e caberia a Flasan simplesmente seguir os "princípios estabelecidos por eles".

Para Beauchamp, a história é uma narrativa que, como dizia Luciano, não admitia "a mais ligeira mentira". Essa afirmativa não impedia que ele comparasse a história ao drama. Medeiros (2012, p. 152) refuta tal afirmativa: "[...] a história era tão oposta ao drama quanto a ação da narração. Aproximá-los ou assimilá-los seria um erro, demonstrável pela simples definição das palavras." Nesse sentido, Flasan não aceitava a comparação entre drama e história: para ele, a "história era um lugar reservado à verdade, e trazer elementos da poesia e do drama seria transformá-la em um lugar de mentira de falsidade [...]" (MEDEIROS 2012, p. 152).

Michel de Certeau (1982, p. 10) esclarece que a historiografia (que significa história e escrita) carrega consigo no próprio conceito o paradoxo: "[...] e quase o oximoro - do relacionamento de dois termos antinômicos: o real e o discurso. Ela tem a tarefa de articulá-los e, onde este laço não é pensável, fazer como se os articulasse [...]." Foi justamente a relação estabelecida entre o discurso e o real a que motivou Certeau a escrever a obra A Escrita da História.

Beauchamp várias vezes declarou ser um historiador do tempo presente, mas não acreditava que sua obra fosse uma "espécie de crônica cotidiana" assim como as realizadas pelos jornalistas. Ele defendia que os seus trabalhos tinham uma grande relevância para a posterioridade. Como foi possível perceber e como conclui Medeiros (2012, p. 164-165), as acusações a Beauchamp e a outros historiadores que se inspiravam no modelo dos antigos de escrever história "revelam o surgimento de uma nova atitude em relação não só à Antiguidade, mas ao passado como um todo". Não bastava apenas escrever sobre a história, era preciso também comprovar os fatos relatados. Em consonância com a afirmação feita por mim anteriormente a respeito das possíveis aproximações entre alguns dos pressupostos de Marc Bloch e Alphonse Beauchamp, Medeiros finaliza o seu excelente trabalho constatando que a maior lição que o historiador francês deixou para os historiadores das gerações seguintes é a de que não necessariamente o passado está morto, mas, como sabemos, o presente é dotado de uma urgência, sendo a história uma ciência que se mantém viva.

\section{Referências bibliográficas}

BLOCH, Marc. Introdução à História. Rio de Janeiro: Jorge Zahar, 2001.

CERTEAU, Michel de. A Escrita da História. Rio de Janeiro: Forense Universitária, 1982.

FROTA, Luciana Silveira de Aragão e. História e Historiadores num Mundo de Conhecimento. In: AVELINO, Yvone Dias; CARVALHO, Alex Moreira; FLÓRIO, Marcelo (orgs.). História, Cotidiano e Linguagens. São Paulo: Expressão e Arte, 2012, p. 121-137. 